\title{
Genetics and cardiovascular system: influence of human genetic variants on vascular function
}

\author{
Rodrigo Gonçalves Dias • Márcia Maria Gowdak • \\ Alexandre Costa Pereira
}

Received: 7 April 2010/Accepted: 14 October 2010/Published online: 3 November 2010

(C) Springer-Verlag 2010

\begin{abstract}
Candidate gene association studies in cardiovascular diseases have provided evidence on the molecular basis of phenotypic differences between individuals. The comprehension of how inherited genetic variants are able to affect protein functions has increased the knowledge of how genes interact with environment in order to modulate a particular phenotype. Although it is known that the human genome contains more than 10 million SNPs, only a minor part of them are supposed to be functional. A causative SNP in a particular gene may confer a small to moderate effect in complex phenotypes, such as functions important to cardiovascular homeostasis. This paper is a selective review of the literature on the evidence for interactions between vascular function and naturally occurring genetic variants in endothelial nitric oxide synthase (eNOS) and beta-2 adrenergic receptor (ADRB2), two genes among those influencing vascular phenotype and examples for which there is a strong evidence base. eNOS and ADRB2 will be characterized, as well as the mechanisms by which the enzyme and the receptor work to control vascular responses will be described. Understanding the molecular mechanisms underlying gene-mediated vascular function and their modification by genetic variants is expected to
\end{abstract}

R. G. Dias $(\bowtie) \cdot$ M. M. Gowdak · A. C. Pereira

Laboratory of Genetics and Molecular Cardiology - Heart

Institute (InCor), Medical School, University of São Paulo,

Av. Dr. Enéas de Carvalho Aguiar, 44 (10 andar; Bloco II),

Cerqueira César, São Paulo, SP 05403-000, Brazil

e-mail: diasrg99@yahoo.com.br

R. G. Dias

Unit of Hypertension - Heart Institute (InCor),

Medical School, University of São Paulo, São Paulo, Brazil

R. G. Dias

LabCardio, University of Campinas, Campinas, Brazil result in a better comprehension about individual's phenotypic differences.

Keywords Genetic - Genetic variant · Polymorphism · Vascular function - Gene-environment interaction .

Phenotype

\section{Introduction}

Advances in molecular biology have increased the knowledge of how genes control physiological functions involved in the modulation of specific phenotypes. The human genome consists of approximately 25,000 genes codified by approximately 3.1 billion base pairs, distributed in 23 pairs of chromosomes [21]. Considering the fact that the physiological systems of human beings have the same functioning pattern, one could imagine that the DNA sequence might be the same among individuals, at least for those genes codifying proteins involved in common cellular processes such as enzymes and receptors. This rationale seems not to be the case since it is common that nucleotide sequence variations can be identified in any particular gene of any two individuals. These genetic variants can take several forms, comprising a single base pair change, an insertion or deletion of a DNA segment and repetitive elements of DNA. Differences in single bases are by far the most common example of genetic variation, known as single-nucleotide polymorphisms (SNPs). The comparison of DNA sequences of two unrelated individuals has shown the existence of, on average, approximately 1 difference every 1,200 bases. The human genome contains about 10 million SNPs and a minor part of them is located in regulatory regions of genes and in protein coding sequences [4]. There are approximately 100,000 SNPs in 
the protein coding regions of the genome. Many of these variants might be relevant for studies of human health and disease since they may alter an amino acid sequence or disrupt a motif that affects the function or structure of a protein involved in a biological process. While mutations are rare and maybe unique to an individual, polymorphisms are found in many individuals, at a specific frequency, usually $1 \%$ or greater in a particular population. In this case, a functional genetic variant affecting a specific protein may confer a small to moderate effect in a specific trait. This concept is particularly appealing in complex phenotypes, such as cardiovascular structure and function, which are controlled by a large number of genes. The knowledge about genes and SNPs function is crucial to establish the scientific basis for how genes interact with the environment in order to cause a particular phenotype. Nevertheless, while the assessment of a candidate variant on the basis of nucleotide sequence is relatively easy, the subsequent confirmation of its functional significance is usually more difficult. This is a major challenge affecting genetic association studies, which have the aim of assessing correlations between genetic variants and trait differences on a population scale. Exemplifying, a positive association between a variant in a candidate gene with a specific altered phenotype may not mean that the gene in consideration is responsible for the alteration. This gene might be in linkage disequilibrium with a truly causative variant or, perhaps, the association might represent a falsepositive result. In case of disequilibrium, it means that the allele in a supposed causative gene under study is not inherited randomly, but together with a nearby and truly causative allele. This happens because close-linked genetic markers in a chromosome are not easily separated by recombination. In this situation, the allele located in that supposed causative gene works as a marker SNP for another causative SNP. The difficulty in identifying truly causative genes in association studies is also due to the synergistic effect of multiple genetic variants interacting with environmental factors in order to modulate a phenotype [36, 37]. Biologically relevant SNPs can alter cellular processes conferring an increased protection in some cases and a greater susceptibility to disease in other. Interestingly, environmental variables such as diet and exercise are able to interact with genes chronically activated during disease states, affecting disease progression. As the number of studies with diet- and exercise-gene interactions has increased, it is reasonable to expect, in the near future, the application of "personalized intervention" in health and disease, based on a set of SNPs in specific groups of genes.

This article will provide a brief overview of the complex interaction between genes and environmental factors in the control of vascular functions. Although a large number of genes influence vascular reactivity, to intentionally illustrate this complexity, this review will address specially the interactions involving two genes, endothelial nitric oxide synthase (eNOS) and beta-2 adrenergic receptor (ADRB2). There are an increasing number of published studies that have investigated their influence on vascular function, and they are examples for which there is strong evidence base. How eNOS and ADRB2 genotypes alter the harmful and beneficial impact of environment will be shown to illustrate gene-environment interaction in such scenarios. eNOS and ADRB2 genes will be molecularly described with the purpose of improving the comprehension of the mechanisms by which each protein interacts with others in their pathways to trigger cellular processes.

\section{Nitric oxide, $\boldsymbol{\beta}_{2}$-adrenoreceptors and vascular reactivity}

While this review concentrates mainly on the role of nitric oxide and beta- 2 adrenergic receptor in humans, it is important to note that other vasoactive substances control vascular tone as well. In this regard, endothelium plays a direct role in vasomotor function by integrating stimuli such as sympathetic discharge, mechanical forces, humoral and local factors. Among those endothelial-derived substances, nitric oxide, prostaglandins and endotheliumderived hyperpolarizing factor (EDHF) can be cited as vasorelaxing factors. On the other hand, endothelin, superoxide $\left(\mathrm{O}_{2}-\right)$ and thromboxane can be cited as vasoconstricting factors. For a better understanding of the role of these molecules and their function as vasoactive substances, we refer the readers to these papers $[3,22,39$, 41, 47].

Nitric oxide (NO) is an important signaling molecule which is synthesized from L-arginine by a family of enzymes called NO synthase (NOS). NO, an endotheliumderived relaxing factor (EDRF), is recognized as a vasoactive factor in the cardiovascular system mainly by its capacity to induce vasodilation and inhibit platelet aggregation $[14,15]$. There is a basal NO release from the vascular endothelium and increases in NO discharge can be mechanically evoked by stimuli such as higher blood flow [31]. The proposed mechanism by which NO is synthesized in endothelial cells by eNOS leading to vascular smooth muscle relaxation is shown in Fig 1.

In humans, $\beta_{2}$-adrenoreceptors mediate physiologic responses such as vasodilatation, bronchial smooth muscle relaxation and lipolysis [8]. Stimulation of $\beta_{2}$-adrenoreceptors by catecholamines on vascular smooth muscle results in vasodilatation by an endothelium-independent mechanism. Additionally, $\beta_{2}$-adrenoreceptors-mediated vasodilatation has been linked to an increased activity of the L-arginine/NO pathway $[13,28]$. The proposed mechanism by which $\beta_{2}$-adrenoreceptors activation on the 


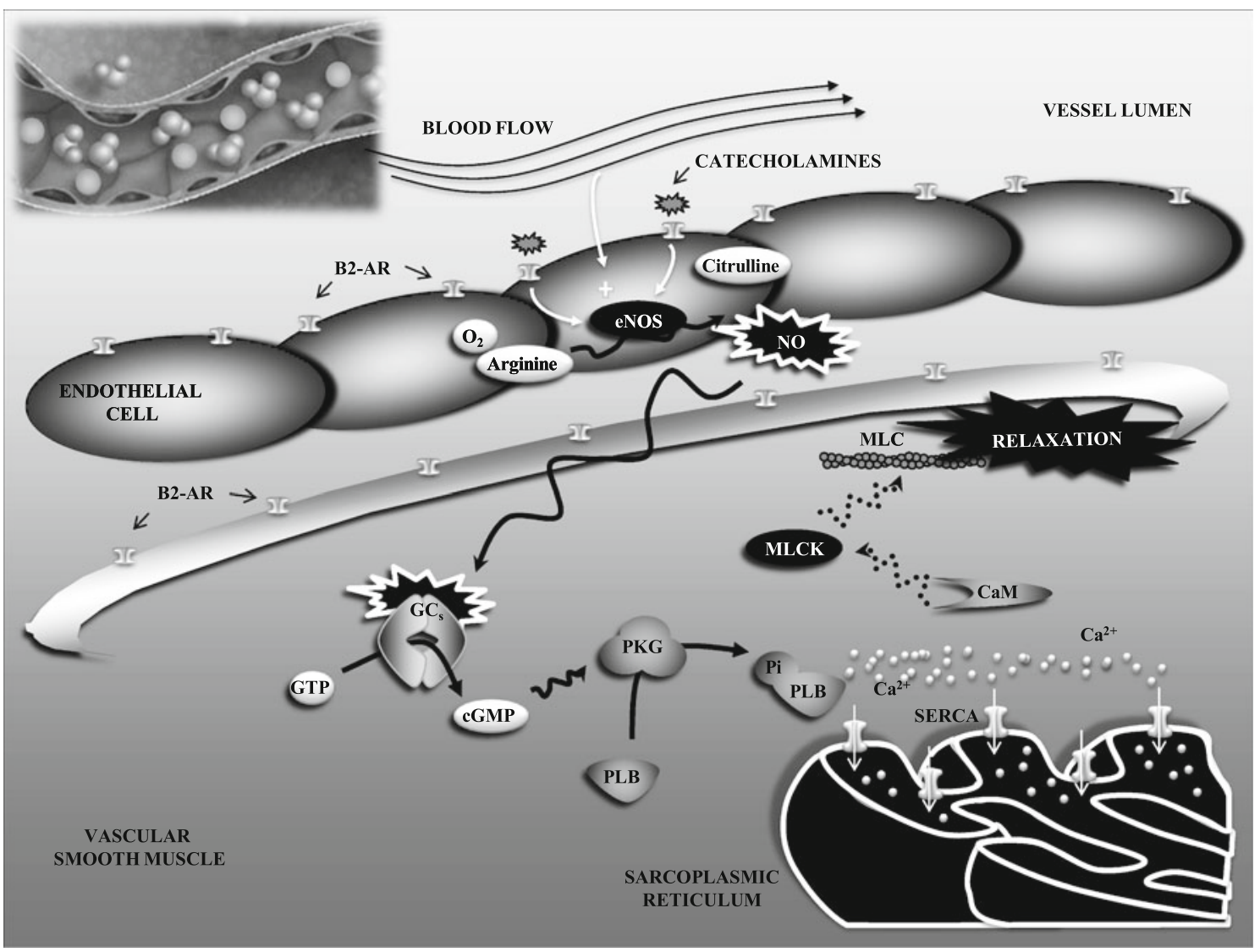

Fig. 1 Proposed mechanism by which nitric oxide (NO) synthesized by endothelial NO synthase (eNOS) induces relaxation in smooth muscle and increase vasodilatation. Shear stress, a frictional force exerted on the vessel surface by blood flow and stimulation of $\beta_{2}$-adrenoceptors, activates eNOS. NO, acting in a paracrine manner, stimulates soluble guanylyl cyclase (GCs) in vascular smooth muscle causing guanosine $3^{\prime}, 5^{\prime}$-cyclic monophosphate (cGMP) rise. cGMPdependent protein kinase (PKG) activates the uptake of $\mathrm{Ca}^{2+}$ into the superficial sarcoplasmic reticulum (SR) by the phosphorylation of phospholamban (PLB) and subsequently activation of SR $\mathrm{Ca}^{2+}$ ATPase (SERCA). Myosin light chain (MLC) phosphorylation is

vascular endothelium contributes to vascular smooth muscle relaxation is shown in Fig 1.

\section{Nitric oxide synthase gene}

There are three isoforms of NOS codified by distinct genes: endothelial NOS (eNOS or NOS III; 7q35-36); neuronal NOS (nNOS or NOS I; 12q24.2); and inducible NOS (iNOS or NOS II; 17cen-q12). eNOS and nNOS are constitutively expressed, while iNOS is expressed in abnormal cell processes such as those occurring in heart failure [12] and after induction by cytokines and other inflammatory agents, which results in a high NO flow [1]. The eNOS gene is mainly expressed in endothelial cells and it is essential for baseline vascular tone maintenance. necessary for actin activation of myosin ATPase, resulting in crossbridge cycling. This phosphorylation is mediated by myosin light chain kinase (MLCK), a calcium/calmodulin-activated kinase. Since intracellular calcium is diminished by the increased influx into the superficial SR, the resultant effect is smooth muscle relaxation. eNOS endothelial nitric oxide synthase, $N O$ nitric oxide, $B 2-A R$ beta2-adrenoreceptor, GCs soluble guanylyl cyclase, $c G M P$ guanosine $3^{\prime}, 5^{\prime}$-cyclic monophosphate, $P K G$ cGMP-dependent protein kinase, $P L B$ phospholamban, $M L C$ myosin light chain, $M L C K$ myosin light chain kinase, SERCA sarcoplasmic reticulum $\mathrm{Ca}^{2+}$-ATPase

The eNOS gene is located in chromosome 7q35-36 and comprises 26 exons that encode a $135-\mathrm{kD}$ protein containing 1,203 amino acids. Variations in nucleotide sequence have been described in the promoter, exons and intronic regions [20]. These variations may result in differences in gene expression and may modulate interindividual differences in the activity of the encoded protein. These variations might predispose or increase an individual's susceptibility to the development of cardiovascular outcomes. As such, a polymorphic allele would be expected to be over-represented in populations of affected individuals, compared to healthy controls. Among the common genetic polymorphisms identified in the eNOS gene, the $-786 \mathrm{~T}>\mathrm{C}$ (rs2070744) and 894G $>\mathrm{T}$ ( $\mathrm{rs} 1799983$ ), located in the $5^{\prime}$-flanking region of the gene and in the exon 7 region, respectively, seem to affect cardiovascular phenotypes. 
Differences in vascular reactivity to phenylephrine, an $\alpha_{1}$-adrenoceptor agonist, are commonly observed in patients undergoing cardiopulmonary bypass. Philip et al. [38] identified that individuals with 894GT and 894TT genotypes of the eNOS $894 \mathrm{G}>\mathrm{T}$ polymorphism showed similar increase in mean blood pressure but with lower phenylephrine doses, than $894 \mathrm{GG}$ genotype carriers. This result suggests that the eNOS $894 \mathrm{G}>\mathrm{T}$ polymorphism may affect vascular responsiveness to $\alpha$-adrenergic stimulation. In another study, Naber et al. [35] investigated coronary vasomotor tone in patients undergoing routine diagnostic cardiac catheterization for unclear chest pain. By means of intracoronary Doppler, they found no difference, at rest, in the cross-sectional area among eNOS $894 \mathrm{G}>\mathrm{T}$ genotypes, but increased coronary vascular resistance and decreased average peak velocity in individuals harboring the 894TT genotype, more so than in other genotypes. Since epicardial vasomotor tone, which is represented by cross-sectional area, was not different among genotypes, the authors concluded that the supposed decreased eNOS enzyme activity in 894TT genotype carriers affects primarily the microvascular circulation, reflected by increased coronary vascular resistance and subsequent decreased average peak velocity. Suzuki et al. [43] investigated a possible association between the eNOS $894 \mathrm{G}>\mathrm{T}$ polymorphism and coronary in-stent restenosis and found that the restenosis rate is higher among those carriers of the $894 \mathrm{~T}$ allele. The positive results of these genetic association studies suggest that the protein encoded by the mutant allele may have impaired activity. Genetic variants in gene promoters have the potential to influence mRNA transcription, while those in gene exons, predicting amino acid substitution in the mature protein, have the potential to alter enzyme activity. The authors recognize that functional analysis would be necessary to confirm whether the observed vascular alterations are secondary to the eNOS 894T allele.

The eNOS $894 \mathrm{G}>\mathrm{T}$ polymorphism results in the exchange of Glutamate (Glu) to Aspartate (Asp) at position 298 of the encoded protein. Interestingly, enzymatic studies for both, recombinant Asp298 and Glu298, showed no differences in enzyme activity, suggesting that the resultant amino acid substitution does not exert any functional effect via a mechanism dependent of NOS catalysis [20]. Nevertheless, it was shown by Tesauro et al. [44] that the Asp298 variant is more susceptible to proteolytic cleavage in endothelial cells and vascular tissues, which might result in reduced levels of functional eNOS. This result was criticized by the fact that the Asp298 increased susceptibility for proteolytic cleavage, observed in vitro, could be an artifact of nonspecific acid hydrolysis during sample preparation [11]. Although there is no conclusion about the underlying mechanism responsible for the reduced eNOS Asp298 functionality, some studies have observed that dysfunctions appear to be dependent of the Asp298 variant.

Endothelium-dependent mammary artery rings relaxation of patients undergoing coronary bypass surgery was measured in vitro. The carriers of $-786 \mathrm{C}$ allele of eNOS $-786 \mathrm{~T}>\mathrm{C}$ polymorphism or $894 \mathrm{~T}$ allele of eNOS $894 \mathrm{G}>\mathrm{T}$ polymorphism showed blunted acetylcholine-mediated relaxation, more so than in wild type for both polymorphisms. Additionally, among carriers of mutant alleles, those with more than three cardiovascular risk factors showed further aggravation of endothelial dysfunction compared with those with less than three risk factors [10]. These results exemplify the complex interaction between genes and environmental factors, as the eNOS variants represented an additional biological impact for those with more than three cardiovascular risk factors. Considering this idea, are eNOS gene polymorphisms functional in healthy conditions? To test this hypothesis, Dias et al. [7] investigated the potential influence of eNOS $894 \mathrm{G}>\mathrm{T}$ polymorphism in exercise-induced reflex muscle vasodilatation in healthy volunteers. Forearm vasodilatation was blunted in 894TT genotype carriers, more so than in 894GG and 894TT genotypes carriers. Since this result would be mediated by increased sympathetic nerve activation and not by the eNOS $894 \mathrm{G}>\mathrm{T}$ polymorphism, the authors studied exercise-induced reflex muscle vasodilatation under blockage of eNOS enzyme activity and direct measure of muscle sympathetic nerve activity. They found no difference in sympathetic discharge-mediated vasoconstriction among 894GG and 894TT genotypes carriers. On the other side, $N^{\mathrm{G}}$-monomethyl-L-arginine (L-NMMA), a NOS enzyme active blocker, significantly reduced muscle vasodilatation in $894 \mathrm{GG}$, but not in 894TT genotype carriers. This result showed association of eNOS 894T allele with impaired enzyme activity suggesting that, even in healthy conditions, this genetic variant may predict a higher susceptibility to certain cardiovascular diseases.

It is well known that exercise training improves endothelial function, either in healthy or disease states [27, 46]. In regard to eNOS gene polymorphisms, Erbs et al. [9] investigated the potential effect of exercise traininginduced endothelial improvement in coronary artery disease patients. Interestingly, previous to exercise training only 894TT genotype carriers of eNOS $894 \mathrm{G}>\mathrm{T}$ polymorphism showed a paradoxical vasoconstriction response to acetylcholine of the left internal mammary artery. After 4 weeks of training, the improvement in vasodilatory capacity was blunted in 894TT genotype, more so than in the other genotypes, including the genotypes of eNOS $-786 \mathrm{~T}>\mathrm{C}$ polymorphism. In addition, in those $-786 \mathrm{TC}$ genotype carriers of eNOS $-786 \mathrm{~T}>\mathrm{C}$ polymorphism, the improvement in vasodilatory capacity was blunted, more so 
than in carriers of the 894GT and 894TT genotypes of eNOS $894 \mathrm{G}>\mathrm{T}$ polymorphism. Although changes in endothelial function varied depending on eNOS gene variants, the authors recognize the importance of exercise training as a nonpharmacological approach in cardiac rehabilitation programs.

There is a particular interest in the comprehension of how inherited genetic variants are able to affect the degree of influence of environmental factors in particular phenotypes. Leeson et al. [25] investigated, in young volunteers of both genders, the interaction between eNOS $894 \mathrm{G}>\mathrm{T}$ polymorphism and two factors affecting vascular reactivity: the proatherogenic risk factor of cigarette smoking and the antiatherogenic influence of n-3 fatty acid intake. In male smokers, carriers of the 894GT and 894TT genotypes showed reduced flow-mediated dilatation compared with nonsmokers. Interestingly, smoking seems to not affect flow-mediated dilatation in males with 894GG genotype and in females with the three genotype groups for the eNOS $894 \mathrm{G}>\mathrm{T}$ polymorphism. The authors suggest that, probably due to estrogen-mediated vasculoprotective action under the endothelium, premenopausal females follow a different pattern than men. In regard to n-3 fatty acid status, there was a positive association between plasma n-3 fatty acid levels and flow-mediated dilatation in 894T allele carriers (heterozygous plus homozygous). In this case, the results were similar between males and females. Although the mechanism for this interaction is not clear, raised levels of n-3 fatty acids have been shown to regulate gene expression and are associated with greater membrane fluidity. Considering the results of this study, the authors recognize that genetic effects on cardiovascular disease need to be investigated in conjunction with other modifying environmental factors to determine their impact on vascular disease development.

Since NO has an important role in normal vascular homeostasis, the reduction in its endothelial bioavailability is recognized as an important feature of an impending vascular disease state. As reviewed here, eNOS gene variants are associated with differences in vascular reactivity and this has been supported in some investigations by means of functional analysis. It provides evidence of how genes increase susceptibility to diseases and how genes interact with environment factors to modulate a specific phenotype. eNOS gene variants explain, at least in part, differences in susceptibility to cardiovascular complications and how they respond to interventions.

\section{Beta-2 adrenergic receptor gene}

The beta-2 adrenergic receptor gene (ADRB2) is expressed in vascular smooth muscle and in vascular endothelium.
ADRB2 gene is located in the chromosome 5q31-q32. It is highly polymorphic and many naturally occurring SNPS were identified among different populations. Variations in gene nucleotide sequence can alter amino acid sequence of the protein and this may alter the receptor ligand binding and its down-regulation following agonist exposure. The substitution of glycine for arginine at position 16 (Arg16Gly polymorphism; rs1042713) and the substitution of glutamic acid for glutamine at position 27 (Gln27Glu; rs 1042714) are the most common SNP changes observed in the general population and seem to alter the receptor functional properties in different manners [5]. In addition, they might affect the function of the receptor in vitro and in vivo [24, 26]. The in vitro analysis showed that the Arg16Gly variant is associated with enhanced agonistinduced desensitization, and the Gln27Glu variant is associated with resistance to desensitization, relative to the responses associated with products of wild-type alleles, Arg16 and Gln27, respectively [17].

In vivo, Cockcroft et al. [5] demonstrated a relationship between the Gln27Glu $\beta_{2}$-adrenoreceptor variant and forearm vascular reactivity to isoproterenol. Compared with a group of individuals homozygous for the Gln27, the homozygous for the Glu27 $\beta_{2}$-adrenoreceptor allele have an increased vasodilator response to infused isoproterenol. An investigation has shown a marked disequilibrium between the polymorphisms at codons 16 and 27 of the $\beta_{2}$-adrenoreceptor [8]. Thus, almost all persons who are homozygous for Glu27 are also homozygous for Gly16, whereas persons who are homozygous for Gly16 can be homozygous for Gln27, homozygous for Glu27, or heterozygous at codon 27.

Trombetta et al. [45] reported an augmented reflex muscle vasodilatory response during physiological maneuvers in women who are homozygous for Gly16/ Glu27 of the $\beta_{2}$-adrenoreceptor. In this study, the carriers of the allele Glu27 showed increased forearm vasodilatation during mental stress and handgrip exercise, regardless of the mutation encoding for the amino acids at position 16 . Propranolol infusion into the brachial artery abolished the difference in forearm vasodilatory response between Gly16/Glu27 and Arg16/Gln27 women. These findings suggest a strong influence of Gly16/Glu27 $\beta_{2}$-adrenoreceptor variants in the receptor functionality.

Recently, one study from our group demonstrated that a high-fat meal reduces muscle vasodilatation during mental stress in healthy individuals. Moreover, the muscle vasodilatation reduction was markedly greater in individuals who were homozygous for the Glu27 allele of the ADRB2 gene than in those who were homozygous for the Gln27 allele [16]. As already proposed by previous studies, a high-fat meal increases plasma triglyceride levels, which may then lead to endothelial dysfunction by lowering 
LDL-cholesterol particles and making them prone to oxidation [33]. The presence of oxidized products in the endothelium decreases nitric oxide synthase activity and impairs vasodilatation [18]. Based on the described link between high-fat meal ingestion, NO production and vasodilatation, the authors believe that the impaired vasodilatation response to mental stress seen after a high-fat ingestion by individuals who were homozygous for the Glu27 allele might be due to a greater dependency on NO synthesis in this particular subset of individuals.

The possibility that changes in the expression of the $\beta_{2}$-adrenoreceptors due to polymorphisms might have phenotypic consequences influencing their cardiovascular or metabolic function is an idea that has attracted much attention during the last years. Because individuals who are homozygous for Glu27 $\beta_{2}$-adrenoreceptor allele have greater vasodilatory response, some studies have speculated if those individuals could be somehow protected against cardiovascular disorders. Mansur et al. [29] were not able to demonstrate an influence of Gln27Glu and Arg16Gly $\beta_{2}$-adrenoreceptor variants on the prognosis of patients with heart failure. In addition, the allele Glu27 showed no association with preclinical atherosclerosis [19] but, on the other hand, it may represent a potential risk factor for fat accumulation and obesity in women [23, 24]. Another recent study suggested that individuals homozygous for Glu27 allele of $\beta_{2}$-adrenoreceptor had a decreased risk of myocardial infarction, compared to Gln27 homozygote subjects [48]. A reduction in cardiovascular events has been found in some $[42,48]$ but has not been replicated in other investigations $[2,40]$. Moreover, a combination of the Arg16Gly and Glu298Asp (c.894G $>$ T of eNOS) polymorphisms in $\beta_{2}$-adrenoreceptor and endothelial nitric oxide synthase genes, respectively, increased the risk for hypertension in elderly humans [34].

The importance of the ADRB2 gene goes beyond its role in vascular function, as described above, further adding to the complexity of gene-environment interactions and the resulting phenotype. It has been shown that the ADRB2 gene has also an important participation in energy-expenditure regulation as it encodes a major lipolytic receptor protein in human fat cells, what could partially explain the link between obesity and the Gln27Glu variant [30]. The presence of the Glu27 allele seems to influence the individual response to diet and physical activity [30]. A casecontrol study has found a significant interaction between obesity risk and levels of carbohydrate consumption above $49 \%$ total energy for carriers of the Glu27 allele of the $\beta_{2}$-adrenoreceptor [32]. Another investigation found that carriers of the Glu27 allele who were more active in their leisure time had a higher BMI compared to the noncarriers. Such results suggest that carriers of the Glu27 allele of the $\beta_{2}$-adrenoreceptor may represent a resistance to losing weight under nonpharmacological treatments, such as diet and physical activity [6]. This demonstrates that a single SNP in a particular gene may confer different functional properties of the respective coded-protein in different physiological systems in a same individual.

\section{Conclusion}

There are common genetic variants identified in nitric oxide synthase and beta- 2 adrenergic receptor genes. Some of them are functionally important and influence vascular response. The interaction between these functional gene polymorphisms and environmental factors may play a substantial role in the risk of cardiovascular diseases. Despite the attractive scenario that has emerged with regards to the studies of diet- and exercise-gene interactions, to date, current results are not enough to start prescribe specific personalized interventions. As discussed above, vascular reactivity is controlled by a large number of genes and each one confers only a small to moderate effect in such phenotype. Nevertheless, the progression in functional genomics understanding promises a revolution in health care. As our understanding of the interplay between genetics and cardiovascular function increases, the optimistic expectation is that, in the near future, cardiovascular genetics could be integrated into clinical practice.

\section{References}

1. Alderton WK, Cooper CE, Knowles RG (2001) Nitric oxide synthases: structure, function and inhibition. Biochem $\mathrm{J}$ 357:593-615

2. Barbato E, Berger A, Delrue L, Van Durme F, Manoharan G, Boussy T, Heyndrickx GR, De Bruyne B, Ciampi Q, Vanderheyden M, Wijns W, Bartunek J (2007) GLU-27 variant of beta2adrenergic receptor polymorphisms is an independent risk factor for coronary atherosclerotic disease. Atherosclerosis 194:e80-e86

3. Bouallegue A, Daou GB, Srivastava AK (2007) Nitric oxide attenuates endothelin-1-induced activation of ERK1/2, PKB, and Pyk2 in vascular smooth muscle cells by a cGMP-dependent pathway. Am J Physiol Heart Circ Physiol 293:H2072-H2079

4. Cargill M, Altshuler D, Ireland J, Sklar P, Ardlie K, Patil N, Shaw N, Lane CR, Lim EP, Kalyanaraman N, Nemesh J, Ziaugra L, Friedland L, Rolfe A, Warrington J, Lipshutz R, Daley GQ, Lander ES (1999) Characterization of single-nucleotide polymorphisms in coding regions of human genes. Nat Genet 22:231-238

5. Cockcroft JR, Gazis AG, Cross DJ, Wheatley A, Dewar J, Hall IP, Noon JP (2000) Beta(2)-adrenoceptor polymorphism determines vascular reactivity in humans. Hypertension 36:371-375

6. Corbalan MS, Marti A, Forga L, Martinez-Gonzalez MA, Martinez JA (2002) The 27Glu polymorphism of the beta2-adrenergic receptor gene interacts with physical activity influencing obesity risk among female subjects. Clin Genet 61:305-307

7. Dias RG, Alves MJ, Pereira AC, Rondon MU, Dos Santos MR, Krieger JE, Krieger MH, Negrao CE (2009) Glu298Asp eNOS 
gene polymorphism causes attenuation in non-exercising muscle vasodilatation. Physiol Genomics 37(2):99-107

8. Dishy V, Sofowora GG, Xie HG, Kim RB, Byrne DW, Stein CM, Wood AJ (2001) The effect of common polymorphisms of the beta2-adrenergic receptor on agonist-mediated vascular desensitization. N Engl J Med 345:1030-1035

9. Erbs S, Baither Y, Linke A, Adams V, Shu Y, Lenk K, Gielen S, Dilz R, Schuler G, Hambrecht R (2003) Promoter but not exon 7 polymorphism of endothelial nitric oxide synthase affects training-induced correction of endothelial dysfunction. Arterioscler Thromb Vasc Biol 23:1814-1819

10. Erbs S, Mobius-Winkler S, Linke A, Adams V, Doll N, Gielen S, Gummert JF, Mohr FW, Schuler G, Hambrecht R (2006) Both T-786C and G894T polymorphism of endothelial nitric oxide synthase affect in vitro endothelium-dependent relaxation of internal mammary artery rings from patients with coronary artery disease. Eur J Cardiovasc Prev Rehabil 13:826-831

11. Fairchild TA, Fulton D, Fontana JT, Gratton JP, McCabe TJ, Sessa WC (2001) Acidic hydrolysis as a mechanism for the cleavage of the Glu(298) $\rightarrow$ Asp variant of human endothelial nitric-oxide synthase. J Biol Chem 276:26674-26679

12. Ferreiro CR, Chagas AC, Carvalho MH, Dantas AP, Scavone C, Souza LC, Buffolo E, da Luz PL (2004) Expression of inducible nitric oxide synthase is increased in patients with heart failure due to ischemic disease. Braz J Med Biol Res 37:1313-1320

13. Ferro A, Queen LR, Priest RM, Xu B, Ritter JM, Poston L, Ward JP (1999) Activation of nitric oxide synthase by beta 2-adrenoceptors in human umbilical vein endothelium in vitro. $\mathrm{Br} \mathbf{J}$ Pharmacol 126:1872-1880

14. Förstermann U (2006) Janus-faced role of endothelial NO synthase in vascular disease: uncoupling of oxygen reduction from NO synthesis and its pharmacological reversal. Biol Chem 387:1521-1533

15. Furchgott RF, Zawadzki JV (1980) The obligatory role of endothelial cells in the relaxation of arterial smooth muscle by acetylcholine. Nature 288:373-376

16. Gowdak MM, Laterza MC, Rondon MU, Trombetta IC, Pereira AC, Krieger JE, Negrao CE (2010) A high-fat meal impairs muscle vasodilatation response to mental stress in humans with Glu27 beta2-adrenoceptor polymorphism. Lipids Health Dis 9:55

17. Green SA, Turki J, Innis M, Liggett SB (1994) Amino-terminal polymorphisms of the human beta 2-adrenergic receptor impart distinct agonist-promoted regulatory properties. Biochemistry 33:9414-9419

18. Hein TW, Liao JC, Kuo L (2000) oxLDL specifically impairs endothelium-dependent, NO-mediated dilation of coronary arterioles. Am J Physiol Heart Circ Physiol 278:H175-H183

19. Hellstrom L, Large V, Reynisdottir S, Wahrenberg H, Arner P (1999) The different effects of a Gln27Glu beta 2-adrenoceptor gene polymorphism on obesity in males and in females. J Intern Med 245:253-259

20. Hingorani AD (2001) Polymorphisms in endothelial nitric oxide synthase and atherogenesis: John French Lecture 2000. Atherosclerosis 154:521-527

21. International Human Genome Sequencing Consortium (2004) Finishing the euchromatic sequence of the human genome. Nature 431:931-945

22. Ignarro LJ, Cirino G, Casini A, Napoli C (1999) Nitric oxide as a signaling molecule in the vascular system: an overview. J Cardiovasc Pharmacol 34:879-886

23. Jalba MS, Rhoads GG, Demissie K (2008) Association of codon 16 and codon 27 beta 2 -adrenergic receptor gene polymorphisms with obesity: a meta-analysis. Obesity (Silver Spring) 16:20962106

24. Large V, Hellstrom L, Reynisdottir S, Lonnqvist F, Eriksson P, Lannfelt L, Arner P (1997) Human beta-2 adrenoceptor gene polymorphisms are highly frequent in obesity and associate with altered adipocyte beta- 2 adrenoceptor function. J Clin Invest 100:3005-3013

25. Leeson CP, Hingorani AD, Mullen MJ, Jeerooburkhan $\mathrm{N}$, Kattenhorn M, Cole TJ, Muller DP, Lucas A, Humphries SE, Deanfield JE (2002) Glu298Asp endothelial nitric oxide synthase gene polymorphism interacts with environmental and dietary factors to influence endothelial function. Circ Res 90:1153-1158

26. Leineweber K, Buscher R, Bruck H, Brodde OE (2004) Betaadrenoceptor polymorphisms. Naunyn Schmiedebergs Arch Pharmacol 369:1-22

27. Maeda S, Tanabe T, Otsuki T, Sugawara J, Iemitsu M, Miyauchi T, Kuno S, Ajisaka R, Matsuda M (2004) Moderate regular exercise increases basal production of nitric oxide in elderly women. Hypertens Res 27:947-953

28. Majmudar NG, Anumba D, Robson SC, Ford GA (1999) Contribution of nitric oxide to beta2-adrenoceptor mediated vasodilatation in human forearm arterial vasculature. Br J Clin Pharmacol 47:173-177

29. Mansur AJ, Fontes RS, Canzi RA, Nishimura R, Alencar AP, de Lima AC, Krieger JE, Pereira AC (2009) Beta-2 adrenergic receptor gene polymorphisms Gln27Glu, Arg16Gly in patients with heart failure. BMC Cardiovasc Disord 9:50

30. Marti A, Martinez-Gonzalez MA, Martinez JA (2008) Interaction between genes and lifestyle factors on obesity. Proc Nutr Soc $67: 1-8$

31. Martin CM, Beltran-Del-Rio A, Albrecht A, Lorenz RR, Joyner MJ (1996) Local cholinergic mechanisms mediate nitric oxidedependent flow-induced vasorelaxation in vitro. Am J Physiol 270:H442-H446

32. Martinez JA, Corbalan MS, Sanchez-Villegas A, Forga L, Marti A, Martinez-Gonzalez MA (2003) Obesity risk is associated with carbohydrate intake in women carrying the Gln27Glu beta2adrenoceptor polymorphism. J Nutr 133:2549-2554

33. McKeone BJ, Patsch JR, Pownall HJ (1993) Plasma triglycerides determine low density lipoprotein composition, physical properties, and cell-specific binding in cultured cells. J Clin Invest 91:1926-1933

34. Misono M, Maeda S, Iemitsu M, Nakata Y, Otsuki T, Sugawara J, Zempo H, Yoshizawa M, Miyaki A, Kuno S, Matsuda M, Ajisaka $\mathrm{R}$ (2009) Combination of polymorphisms in the beta2-adrenergic receptor and nitric oxide synthase 3 genes increases the risk for hypertension. J Hypertens 27:1377-1383

35. Naber CK, Baumgart D, Altmann C, Siffert W, Erbel R, Heusch G (2001) eNOS 894T allele and coronary blood flow at rest and during adenosine-induced hyperemia. Am J Physiol Heart Circ Physiol 281:H1908-H1912

36. Pereira AC, Floriano MS, Mota GF, Cunha RS, Herkenhoff FL, Mill JG, Krieger JE (2003) Beta2 adrenoceptor functional gene variants, obesity, and blood pressure level interactions in the general population. Hypertension 42:685-692

37. Pereira AC, Sposito AC, Mota GF, Cunha RS, Herkenhoff FL, Mill JG, Krieger JE (2006) Endothelial nitric oxide synthase gene variant modulates the relationship between serum cholesterol levels and blood pressure in the general population: new evidence for a direct effect of lipids in arterial blood pressure. Atherosclerosis 184:193-200

38. Philip I, Plantefeve G, Vuillaumier-Barrot S, Vicaut E, LeMarie C, Henrion D, Poirier O, Levy BI, Desmonts JM, Durand G, Benessiano J (1999) G894T polymorphism in the endothelial nitric oxide synthase gene is associated with an enhanced vascular responsiveness to phenylephrine. Circulation 99:3096-3098

39. Rubanyi GM (1991) Endothelium-derived relaxing and contracting factors. J Cell Biochem 46:27-36

40. Schurks M, Kurth T, Ridker PM, Buring JE, Zee RY (2009) Association between polymorphisms in the beta2-adrenergic 
receptor gene with myocardial infarction and ischaemic stroke in women. Thromb Haemost 101:351-358

41. Sellers MM, Stallone JN (2008) Sympathy for the devil: the role of thromboxane in the regulation of vascular tone and blood pressure. Am J Physiol Heart Circ Physiol 294:H1978-H1986

42. Sotoodehnia N, Siscovick DS, Vatta M, Psaty BM, Tracy RP, Towbin JA, Lemaitre RN, Rea TD, Durda JP, Chang JM, Lumley TS, Kuller LH, Burke GL, Heckbert SR (2006) Beta2-adrenergic receptor genetic variants and risk of sudden cardiac death. Circulation 113:1842-1848

43. Suzuki T, Okumura K, Sone T, Kosokabe T, Tsuboi H, Kondo J, Mukawa H, Kamiya H, Tomida T, Imai H, Matsui H, Hayakawa $\mathrm{T}$ (2002) The Glu298Asp polymorphism in endothelial nitric oxide synthase gene is associated with coronary in-stent restenosis. Int J Cardiol 86:71-76

44. Tesauro M, Thompson WC, Rogliani P, Qi L, Chaudhary PP, Moss J (2000) Intracellular processing of endothelial nitric oxide synthase isoforms associated with differences in severity of cardiopulmonary diseases: cleavage of proteins with aspartate vs. glutamate at position 298. Proc Natl Acad Sci USA 97:28322835

45. Trombetta IC, Batalha LT, Rondon MU, Laterza MC, Frazzatto E, Alves MJ, Santos AC, Brum PC, Barretto AC, Halpern A, Villares SM, Negrao CE (2005) Gly16 + Glu27 beta2-adrenoceptor polymorphisms cause increased forearm blood flow responses to mental stress and handgrip in humans. J Appl Physiol 98:787-794

46. Walther C, Gielen S, Hambrecht R (2004) The effect of exercise training on endothelial function in cardiovascular disease in humans. Exerc Sport Sci Rev 32:129-134

47. Welch WJ (2008) Angiotensin II-dependent superoxide: effects on hypertension and vascular dysfunction. Hypertension 52:5156

48. Yilmaz A, Kaya MG, Merdanoglu U, Ergun MA, Cengel A, Menevse S (2009) Association of beta-1 and beta- 2 adrenergic receptor gene polymorphisms with myocardial infarction. J Clin Lab Anal 23:237-243 